\title{
Hypnopaedia or sleep learning: Overview on methods and results
}

\author{
Hipnopédia ou aprendizagem do sono: Visão geral dos métodos e resultados
}

Hipnopedia o aprendizaje del sueño: Descripción general de métodos y resultados

Received: 04/06/2021 | Reviewed: 04/12/2021 | Accept: 06/11/2021 | Published: 06/12/2021

Sevasti Kapsi
ORCID: https://orcid.org/0000-0002-5214-9304
Institute of Informatics and Telecommunications - Net Media Lab \& Mind-Brain R\&D
Agia Paraskevi, 153 10, Athens, Greece
e-mail: sevastikapsi @ gmail.com
Spyridoula Katsantonis
ORCID: https://orcid.org/0000-0003-1911-3198
Institute of Informatics and Telecommunications - Net Media Lab \& Mind-Brain R\&D
Agia Paraskevi, 153 10, Athens, Greece
e-mail: skatsantoni @ gmail.com
Athanasios Drigas
Mind \& Brain R\&D Net Media Lab, Institute of Informatics and Telecommunications, N.C.S.R. Demokritos, Greece
E-mail: dr@iit.demokritos.gr

\begin{abstract}
Although sleep seems to be an inactive state of mind and body, it is closely connected to memory consolidation and cognitive enhancement. Since memory and learning are strongly related, a new field of research develops, which is called after the term of hypnopaedia or sleep-learning. Knowledge about the functions of sleep, along with techniques that are applied on/after a learning task, contributes to the scientific data about brain boosting. Both Slow Wave Sleep and dreaming, affect cognitive functions. During sleeping, learning gets accelerated, the accuracy in data processing rises, unsolved problems get solved, and entrepreneurial ideas come into light. In the following review of researches about sleep and learning, the most important results are presented.
\end{abstract}

Keywords: Sleep-learning; Memory; Language; Problem-solving; Creativity.

\section{Resumo}

Embora o sono pareça ser um estado inativo da mente e do corpo, ele está intimamente ligado à consolidação da memória e ao aprimoramento cognitivo. Como a memória e o aprendizado estão fortemente relacionados, um novo campo de pesquisa se desenvolve, o qual é denominado por causa do termo hipnopédia ou aprendizado do sono. O conhecimento sobre as funções do sono, juntamente com as técnicas que são aplicadas durante / após uma tarefa de aprendizagem, contribui para os dados científicos sobre o reforço do cérebro. Tanto o sono de ondas lentas quanto os sonhos afetam as funções cognitivas. Durante o sono, o aprendizado é acelerado, a precisão no processamento de dados aumenta, problemas não resolvidos são resolvidos e ideias empreendedoras vêm à tona. $\mathrm{Na}$ seguinte revisão de pesquisas sobre sono e aprendizagem, os resultados mais importantes são apresentados.

Palavras-chave: Aprendizagem durante o sono; Memória; Linguagem; Resolução de problemas; Criatividade.

\section{Resumen}

Aunque el sueño parece ser un estado inactivo de la mente y el cuerpo, está estrechamente relacionado con la consolidación de la memoria y la mejora cognitiva. Dado que la memoria y el aprendizaje están fuertemente relacionados, se desarrolla un nuevo campo de investigación, que se llama después del término de hipnopedia o aprendizaje del sueño. El conocimiento sobre las funciones del sueño, junto con las técnicas que se aplican en / después de una tarea de aprendizaje, contribuye a los datos científicos sobre el aumento del cerebro. Tanto el sueño de onda lenta como el soñar afectan las funciones cognitivas. Durante el sueño, el aprendizaje se acelera, la precisión en el procesamiento de datos aumenta, los problemas no resueltos se resuelven y las ideas empresariales salen a la luz. En la siguiente revisión de investigaciones sobre el sueño y el aprendizaje, se presentan los resultados más importantes.

Palabras clave: Sueño-aprendizaje; Memoria; Lenguaje; Resolución de problemas; Creatividad. 


\section{Introduction}

Sleep is a physical state of mind and body in which minimum activity is observed. Most of our senses stop relating to the stimuli of the environment, the respond to sound becomes scattered and memories of the present are disengaged (Carskadon \& Dement, 2011). Despite this, sleep and memory processing are neuro-biologically and strongly related. Thus, learning keeps on even during sleep, in an off-line mode (Walker, 2008).

Sleep is divided into two kinds of states: NREM sleep and REM (Rapid Eye Movement) sleep. In the first category slow brainwaves appear on the electroencephalogram (EEG), sleep spindles of 12-16 Hz, as well as K-complexes. In this NREM state of sleep, four stages are recorded by EEG. The difference among them is in the speed of the brainwaves: stage 1alpha frequency, stage 2- theta frequency, stage 3-low theta and stage 4-delta frequency. These stages are repeated in a period of 90 to 100 minutes. In the REM state of sleep, the brain appears active and the EEG seems disorganized. REM is the dreaming state that lasts from 1 to 5 minutes, in the first half of sleep, while it increases in number and duration in the second half of sleep period (Peigneux, et al. 2001; Walker \& Stickgold, 2006; Carskadon \& Dement, 2011; Budzynski, 2011).

Learning during sleep is possible by the synaptic- homeostasis mechanism. Tononi \& Cirelli (2003) assume that while the brain is awake, synapses are highly charged. During sleep the synapses are unloaded by the slow brainwaves and get stabilized. In this phase, memory consolidation is achieved, especially after learning tasks.

Cognitive functions are also influenced by physiological mechanisms, during sleep, such as inertia, homeostasis, and circadian rhythms. According to Burke, et al. (2015) inhibition is affected by circadian rhythms, and selective -visual attention is affected by inertia. In addition, sustained-visual attention, working-memory, response-time, mood, vigilance, and motivation are affected by homeostasis and circadian rhythms.

Hypnopaedia is the learning process which takes place during sleep or the ability to learn while sleeping. Although hypnopaedia has been related to pop culture and science fiction, recent neurological research on memory has brought this practice out (Oghenero, 2019).

\section{Method}

The main goal of this article is to present scientific results relative to the process of learning during sleep or relative to the way sleep enhances cognitive abilities, which are fundamental for learning. In this way, we can examine the scientific truth behind the term of hypnopaedia.

The present study is a semi-systematic review. This method permits the investigation of a scientific field which is not well known. Several relevant subjects may come up through research, so we preferred to be open to different research methodologies and studies.

In our review we focused on presenting scientific articles, mostly, peer-grouped. Criteria of inclusion were the following: studies on sleep and learning or cognitive abilities, studies which were published in scientific journals and studies with control group or other groups. We searched in Google Scholar and Mendeley during the period from February 2020 to May 2020. The scientific articles are dated from 2000 to 2020. The research was conducted in the English language. The keywords that were used are the following: "hypnopaedia", "sleep and learning", "sleep and memory", "sleep and language", "sleep and problem-solving" and "sleep and creativity".

This article is divided into sections according to the subjects which occurred from our research and qualitative analysis. The results are presented in a narrative manner and are synthesized in small units. Each unit presents a cognitive ability which correlates to sleep. So, sleep and memory, sleep and language, sleep and problem-solving and sleep and creativity follow. Conclusions are drawn in the end. 


\section{Results}

\subsection{Sleep and memory}

Sleep is claimed to empower performance in memory tasks that are presented before or after sleeping. This is achieved through the different phases and stages of sleep, and through the physiological functions of sleep. According to Stickgold \& Walker (2005) in 81 researches about sleep, from 1995 to 2005, in 62 of them memory consolidation was studied, and this fact was proved in $83 \%$ of them. When can this process be achieved during sleep, in which stages of sleep, by what mechanisms, and to what form of memory? Are there any biomarkers that point out stabilization of memories?

Declarative memory relates to explicit, episodic and semantic memory, while procedural memory relates to implicit memory, skills, and habits. Memory process includes coding of information, consolidation, interaction of information, information recall and confirmation. Sleep favors memory consolidation in both kinds of memory, either before or after the learning process (Walker \& Stickgold, 2006; Walker, 2008).

Memory consolidation is about quantitative and quality changes. This is based on two hypotheses: the two-way hypothesis and the two-steps hypothesis. In the first case declarative memory is enhanced in NREM phase of sleep, while procedural memory is enhanced in REM phase. In the second hypothesis, the hippocampus and the cortex are in a dialogue in slow wave sleep and then REM phase contributes positively in memory consolidation (Peigneux, et al. 2001; Ficca \& Salzarulo, 2004; Ulrich, 2016).

In fact, during Slow Wave Sleep, in NREM phase new coded information interact with previous information, in longterm memory. Hippocampus functions best in deeper stages of sleep. If any sleep disturbance occurs, slow brainwaves are disturbed too. The function of the hippocampus is burdened, when sleep becomes shallower, even if it remains stable in the duration. Consolidation process -that affects the accuracy of information coding- relates to the synaptic discharge, which takes place during sleep, so that the synaptic networks do not exceed in operation. REM phase follows, the synaptic networks get moderated and the reshaped memories are stabilized without any synaptic disturbances. The coordinated brainwave oscillations reactivate memories in the hippocampus and memories are scattered in cortex areas, where plasticity increases, during REM phase. Also, holinergetic, and theta frequency, brainwave activity increase and contribute significantly to memory consolidation. This activation is like a replay of an action or representation. Especially for motor-visual tasks, changes occur in the temporal lobes. Neuronal repetition has been reported by subjects in related experiments, which is also deteriorated when sleep duration increases. Researchers assume that NREM and REM functions are supplementary to memory consolidation (Diekelmann \& Born, 2010; Born, et al., 2006; van Der Werf, et al., 2009).

In accordance with the above mechanisms, special techniques have been developed to enhance memory. These techniques are named after the term Target Memory Reactivation (TMR) and refer to the acoustic or olfactory stimulus that is conditioned to previous to sleep learning and are reactivated during sleep. Several experiments have shown that acoustic stimulus combined with verbal or non verbal learning material and the control of the sex of the voice of the acoustic stimulus decrease oblivion and increase accuracy in recall. TMR also, increases activity in the right hippocampal cortex and the activity that is recorded during acoustic generation in the thalamus, in the temporal lobe and the cerebellum are related to memory accuracy, positively. The brain gets activated in different ways during familiar and unfamiliar acoustic stimuli. This technique greatly affects memory, even in slow oscillations of the brainwaves, as Batterink et al (2016) proved experimentally. It is assumed as a notable technique by many researchers (van Dongen et al., 2012; Oudiette \& Paller, 2013; Creery, et al., 2015; Cairney, et al., 2017; Schreiner, et al. 2017) 
Research, Society and Development, v. 10, n. 7, e2410714721, 2021

(CC BY 4.0) | ISSN 2525-3409 | DOI: http://dx.doi.org/10.33448/rsd-v10i7.14721

Neuronal codes of memory enhancement may me recorded by fMRI or EEG or calcium measures (Chen \& Wilson, 2017). Cairney et al. (2018) studied the activity of neurons, in memory consolidation, after a short or a night sleep ( $N=46$ adults). They adopted the TMR method in the NREM phase and in the second and third stage of sleep. They used paired words and acoustic stimuli. Both recall and word-recognition improved. In addition, sleep spindles increased, so more information had been processed during memory consolidation. Spindles cause neuro-plasticity, their presence proves learning, and communication between the thalamus and the cortical networks. The cortical circuits are synchronized to $7-14 \mathrm{~Hz}$ frequency. In visuo-spatial and verbal memory tasks, sleep spindles are correlated to recall in a linear way and they give rise to calcium in the pyramidal, neocortical cells. Moreover, sleep spindles differ according to age, sex and IQ (Ulrich, 2016).

Marshall et al. (2004) used transcranial Direct Current Stimulation (tDCS) during Slow Wave Sleep (N=30, 23 years old), after declarative and procedural memory learning tasks. They found that a minimum transcranial stimulation can regulate stimulation in the motor-visual and prefrontal cortex, by changing the negative polarization in prefrontal brain areas. In compare to placebo, in tDCS condition declarative memory was enhanced during sleep, but procedural memory was not, in any condition.

Ellenbogen et al. (2009) studied memory consolidation in verbal learning tasks using interference or not, during the learning process. The researchers measured performance either in the condition of sleep or in the condition of sleep deprivation ( $\mathrm{N}=45,18-22$ years old). The results showed that after the sleep condition, recall was better compared to sleep deprivation (16\%), and in the interference condition sleep enhanced the performance (27\%) compared to sleep deprivation.

Fenn et al. (2009) studied the effect of sleep in false memory recall. They used auditory and visual stimuli related to the verbal learning task. They concluded that sleep and combined stimuli can boost episodic memory.

Ngo et al. (2013) studied the effect of acoustic suggestions during low brainwave frequencies $(<1 \mathrm{~Hz})$ in memory performance $(\mathrm{N}=11)$. According to the researchers, these oscillations affect memory consolidation and the acoustic TMR, during this stage of sleep, enhances low oscillations and sleep spindles more. So, declarative memory can get stabilized.

Shimizu et al. (2018) also tested a TMR method with an EEG recorder, which permits researchers to add a sensory stimulus, just in the time when one gets into the NREM phase. Participants ( $\mathrm{N}=37,25$ years old) were trained in a virtual orientation task. During sleep they were administered sounds from the learning environment, where they were trained. This resulted in better performance; more sleep spindles and less time to navigate.

Wamsley et al. (2010) trained 99 individuals (18-30 years old) in a virtual orientation task, too. Half of them were permitted to sleep (till 90 minutes) after the training, while the others were not. As soon as the subjects who were sleeping got into the REM phase, they were awaken and asked about what they had in mind. Most of them were dreaming of the learning task and scored better than the ones who were deprived of sleep. The latter did worse, although they were thinking of the task, while awake.

Shanahan \& Gottfried (2014) reviewed on olfactory TMR techniques, which enhance declarative memory, during sleep. Smell is connected with the limbic system that affects emotions and memory, and it remains active during sleep. If smell is conditioned with other stimuli, then it may enhance their consolidation in memory. The researchers noted that the smell of mint can cause arousal at the second stage of sleep and it is beneficial during the light sleep. Furthermore, the smell of lavender increases Slow Wave Sleep (SWS) and the smell of rose stabilizes information in the same phase. In contrast, auditory TMR can enhance consolidation in any stage of sleep. If sleep is deprived, then no olfactory TMR technique works for memory.

Hu et al. (2006) studied the effect of emotions on declarative memory, during sleep. Sleep and emotions both affect memory consolidation. The researchers tested the impact of emotionally charged memories and neutral memories on the declarative memory ( $\mathrm{N}=14,22,9$ years old). The results showed $42 \%$ better accuracy in identifying emotionally charged 
Research, Society and Development, v. 10, n. 7, e2410714721, 2021

(CC BY 4.0) | ISSN 2525-3409 | DOI: http://dx.doi.org/10.33448/rsd-v10i7.14721

memories and more stabilization. In contrast, Ashton et al. (2018) tested the auditory TMR technique in the recollection of emotionally charged memories, in compare with neutral memories, during SWS ( $\mathrm{N}=20,18-29$ years old). They noticed no differences between memories and they assumed that the sample was small and that they had no control group.

There are also researches on the TMR method, which show negative effects on memory function. Schreiner et al. (2015) trained an experimental and a control group $(\mathrm{N}=16)$ in a vocabulary task. In the experimental group, auditory stimuli were heard during sleep, which were either correctly $(\mathrm{N}=14)$ or false $(\mathrm{N}=13)$ connected to the learning material. The researchers concluded that when the auditory stimuli were correctly connected, the effect of the TMR technique was blocked.

Andrillon et al. (2017) studied how the presence of a new sound during sleep can affect the performance on a learning task in arousal. In their experiment ( $\mathrm{N}=20,20-31$ years old) they exposed people to new noises, during either the REM or the NREM, light sleep stage sleep. They found that the performance was better in this condition. In contrast, when they tried the same in the NREM phase and deep sleep stages of sleep, the performance deteriorated. They concluded that selective memory is active during sleep and -depending on the stage of sleep- may enhance or damage memories.

Finally, Landmann, et al. (2016) studied how the quality of performance can be affected in a verbal and creative learning task, in three conditions (sleep or sleep deprivation or vigilance). They claim that sleep boosts memory, but sleep deprivation organizes memory better and more creatively.

In sum, there is enough neurobiological and performance evidence to support that the physiological function of sleep can boost memory. NREM and REM phases of sleep interact and connect the neural networks of the hippocampus and the cortex, and they increase the volume of the frequencies which lead to memory consolidation. By the usage of TMR techniques during sleep, memory processing keeps on recording, choosing and learning, in different sleep phases, with different results. On the contrary, sleep deprivation undermines memory function, but in some cases it improves memories arrangement. Sleep is enhancive for declarative and procedural memory in verbal and visuo-spatial tasks, both in recognition and recall. Sleep also decreases false memories and supports emotionally charged memories. Boosting or weakening memories is possible, by applying special techniques and that is very interesting.

\subsection{Sleep and Language}

The effect of sleep has been studied in the case of learning vocabulary and foreign languages. Vocabulary learning is closely related to declarative memory and it has been studied along with memory.

Williams \& Horst (2014) studied the effect of bedtime stories on vocabulary learning, in children. It is supported that story telling enhances vocabulary in preschool years, especially if the story is the same each time. The researchers distributed children (3 years old) into four groups: those who took a nap or not in the afternoon, and those who heard the same or different bedtime story. Several measures were conducted on vocabulary and comprehension directly after sleep, 2,5 hours after sleep, 24 hours later and 7 days later. Results showed that sleep and storytelling of the same story enhanced the vocabulary of preschoolers, in contrast to those who did not sleep and heard different stories. Sleep predicted retention of information in the long term memory. Learning was $19 \%$ higher, when children slept and heard the same story. In addition, learning was $33 \%$ higher, when children slept and heard a different story.

Batterink, et al. (2014) studied how sleep can affect grammatical rules in language learning. The researchers taught 29 persons (18-25 years old) several pairs of words in English, which were supposed to imply a hidden grammatical rule. An afternoon nap intervened between two, 20-minutes- lessons. Results showed that those who had more SWS and REM sleep recognized more the grammatical rule. They assume that both phases of sleep contribute to the extraction of complex patterns in language. 
Research, Society and Development, v. 10, n. 7, e2410714721, 2021

(CC BY 4.0) | ISSN 2525-3409 | DOI: http://dx.doi.org/10.33448/rsd-v10i7.14721

In another study (Batterink, et al., 2017) vocabulary learning was associated with TMR technique. Participants (N=26, 20 years old) learned 60 words of an artificial language and their meaning. An afternoon nap followed and auditory TMR with words that were related correctly $(\mathrm{N}=16)$ to the artificial words or incorrectly $(\mathrm{N}=10)$. Results showed significant differences between the conditions, but in most of them REM sleep duration had a major effect. The more REM sleep was recorded, the best performance in related words appeared. Those who had less REM sleep scored higher in the unrelated words. So, REM sleep contributes to consolidation and vocabulary learning and a successive cycle of SWS and REM sleep enhances memory storage.

Moreover, Batterink \& Paller (2017) combined TMR technique with the learning of grammatical rules, in a research with two groups $(\mathrm{N}=35,22,4$ years old). Both groups were taught grammatical rules of an artificial language and sleep followed. In the first group $(\mathrm{N}=17)$ the same grammatical rules were heard in TMR, while in the second group irrelevant sounds were heard. Results presented better generalization of the grammatical rules in the first group, so sleep can enhance grammatical generalization. TMR method during sleep is recommended in the learning process of a second language.

Van Rijn et al. (2017) studied the learning of two Celtic languages (Welsh and Breton) in 80 persons (18-26 years old) who had recently come to Wales. They learned new words and their translation in British and then some of them took an afternoon nap, while others did not. The researchers tested the performance of the two groups, on vocabulary after the nap condition or the alert condition, and 12 hours later. In the nap condition, performance was higher than in the no- sleep condition. The participants had previously evaluated the languages and it was assumed that in the Welsh language, evaluation was related to better performance in this language. In fact, individual differences in the evaluations of the languages affected vocabulary consolidation after the nap. Researchers wonder, if consolidation is only cognitive or emotional, as well.

Schreiner \& Rasch (2017) reviewed the effects of sleep and sensory stimuli during sleep on learning a foreigner vocabulary and grammatical rules. The researchers consider of the TMR technique as a fascinating tool with which one can understand the neuro-mechanisms of sleep and memory. This could change the way one learns a foreign language. Kcomplexes appear in EEG during auditory stimulus in SWS. But if an auditory stimulus is presented at the same time with a sleep spindle, then the auditory cortex is isolated from the auditory stimulus. K-complexes, also appears when one's name is heard during sleep. This technique works only in sleep and not during alertness. There also may be a ceiling effect in the effectiveness of TMR. The effectiveness relates to the increase of theta brain oscillations and the sleep spindles which follow.

We conclude that sleep and language learning are positively related. On the one hand, sleep as a physiological function enhances vocabulary retention, grammatical generalization, when sleep follows learning. On the other hand, TMR may be applied to learning foreigner languages. There is still much research to be conducted on different ages, compared to more classical methods of learning, so as to estimate their effectiveness. Finally, there is an ethical issue in the use of these auditory suggestions, since individuals are not awake. This seems to resemble science fiction scenarios (e.g. Brave New World).

\subsection{Sleep and problem-solving}

Problem-solving is a complicated process, which requires more complex cognitive functions to lead to solutions, besides memory. Is it possible that sleep contributes to this cognitive ability, too?

There are researches about cognitive flexibility and the way this function affects problem-solving, during sleep. Walker et al. (2002) assumed that the REM phase of sleep enhances problem-solving, after a 3,5 -hour -sleep, because the holinergetic system is activated like in the vigilance state. There are many anecdotal stories about the creative way that famous people found solutions to their problems, during sleep (Kekule' and the benzene, Mendeleyev and the periodic table of 
Research, Society and Development, v. 10, n. 7, e2410714721, 2021

(CC BY 4.0) | ISSN 2525-3409 | DOI: http://dx.doi.org/10.33448/rsd-v10i7.14721

elements, Loewi and neurotransmitters, Edison and the electric lamp, etc.). The researchers compared scores in cognitive flexibility tests $(\mathrm{N}=16,20$ years old) that were performed during the day, before a night sleep, during the REM or NREM phase and in the morning. They claim that those who were woken up during the REM phase scored $32 \%$ higher, than those who were woken up during the NREM phase, and scored the same as in alertness. It seems that REM sleep organizes problemsolving differently, compared to the alertness state, but sufficiently enough.

Perogamvros, et al. (2013) reviewed on the dreaming state of REM sleep not only about consolidation, but also about emotions and complicated cognitive processes that relate to problem-solving. During dreaming, the amygdala and medial, limbic, dopaminergic areas increase functioning, so emotions, reward system and information processing. Sleep enhances selective memory consolidation and through dreaming, it activates the processing of emotions, of associative learning, of thinking, of pioneer visions, of cognitive flexibility, and divergent thinking. This results in better arrangement of memories, emotional regulation and creativity.

Sio et al. (2013) studied the effect of sleep on problem-solving (N=61, 20 years old). They used a set of 30 problems that were grated for difficulty and contained words that had a long conceptual distance between them so as to be related. The results showed that the mediation of sleep led to more solutions to the problems, but only for the difficult ones. So sleep is beneficial to problem-solving, only to complex problems.

Beijamini et al. (2014) conducted an experiment on the effect of a nap on problem-solving $(\mathrm{N}=29)$. They assumed that a nap not only boosts memory but creativity and problem-solving, as well. New relations and insights are produced, unspoken ideas become real by the mechanisms of abstraction and distinction. The researchers used actigraphs for a week and then they gave instructions to individuals for a video-game (Speedy Eggbert Mania) and they invite them to play. There was a group that took a nap and another group that stayed calm. In the first group 12 out of 14 solved the riddles, while in the second group 7 out of 15. The researchers stated that individuals were in SWS state and claim that SWS boosts problem-solving by getting access to strategies, that may be more suitable for great challenges.

Monaghan et al. (2015) performed two experiments on the effect of sleep on analogical thinking, in problem-solving. In analogical thinking, several stages of comparison, evaluation and reconstruction of information take place and lead to problem-solving. In the first experiment $(\mathrm{N}=60,20,1$ years old) participants filled in questionnaires and they were given analogical thinking problems. The first group slept during the night and they were examined before sleep and after sleep in the morning. The second group was examined during the day, in the morning and at night, between 12 hours of alertness. Results showed a significant difference between groups which favors the first group and the analogical problems. In the second experiment $(\mathrm{N}=42,19$ years old) the participants were split in two groups that were tested either in the morning or at night. The researchers used the same procedure and found that those who were tested at night scored higher in problem-solving. Nevertheless, statistical analysis of both experiments showed that sleep leads to more solutions in analogical thinking , not as a circadian rhythm, but as a function.

Schönauer, et al.(2018) studied the effect of sleep on problem-solving ( $\mathrm{N}=77,23$ years old). The participants were given tests with many problems such as magic tricks and insight problems. Two groups formed on the base of a sleep interval (3,5 hours), between sessions. Researchers point out that sleep did not affect problem-solving in this kind of problems and that several steps and inspiration come up before a solution.

Briefly, sleep seems to be significant in organizing information during REM and NREM phase in problem-solving. Dreaming is enhancive in difficult problems. Sleep does not only boost the consolidation of memories, but also the arrangement, synthesis and reconstruction of information. There is still research to be conducted to find out about the 
mechanisms and the limitations of sleep function in problem-solving. Problem-solving relates to creativity, conceptually and functionally. So, review on sleep and creativity follows.

\subsection{Sleep and creativity}

Creativity is a more complex concept than problem-solving is. It usually includes the latter, but creativity also refers to the generation of ideas and concepts, concurrently with their materialization in everyday life or in art. How does sleep contribute to this cognitive function?

Insight, during sleep, can get inspirational. Wagner et al. (2004) studied creativity ( $\mathrm{N}=66,18-31$ years old) in three conditions: after an 8-hour-sleep, after 8-hours of alertness, during the night, and in alertness during the daytime. The creativity task included blocks and through experience one could do better. Reaction time gradually decreased, but if they found out the hidden rule of this task, then suddenly they improved their performance. More than half of those who slept found the secret rule, right away. The researchers claim that sleep reconstructs our representations, accesses knowledge and empowers perspective behavior.

Cai et al. (2009) studied the effect of REM sleep on creative problem-solving. They distinguish three phases in problem-solving: $1^{\text {st }}$ intensive phase with conflicts and no results; $2^{\text {nd }}$ decision to put the problem aside; $3^{\text {rd }}$ a period without any effort for solutions; insight during sleep or inactive thinking. They used actigraphs for participants $(\mathrm{N}=77,18-35)$ and sleep diaries, for 5 to 7 days. Then they tested participants with the RAT test (Remote Associates Test), before and after a nap ( 2 hours) or rest. They compared the effectiveness in REM and NREM phase of sleep and compared the results with alertness .The results showed that the REM sleep phase improved $40 \%$ the scores in the test. Networks of information were enhanced and unrelated information was intergraded. This result was not due to memory. The researchers hypothesized that cholinergic and noradrenergic regulation empowers creativity.

Drago et al. (2011) conducted a research on Cyclic Alternating Patterns (CAPs) which are observed during NREM sleep. According to the frequency of CAPs in the EEG, CAPs are distinguished in three types: A1, A2, and A3. The researchers assumed that CAPs relate to creativity. Eight participants' (27 years old) sleep patterns were recorded for three nights and two days later, they took ATTA test (Abbreviated Torrance Test for Adults). This test was about ideas-generation, scenarios, unfilled pictures, geometric shapes and more. Measures on fluency, rarity, detailed description, flexibility and fifteen other creativity rates were made. Results showed positive relation in stage 1 in NREM sleep with fluency and flexibility. There was also positive relation in stage 4 in NREM sleep with originality and the general rate of form construction. A negative relation was manifested in REM sleep and originality, in contrast to the CAPs A1 pattern, that was positively related to originality. In conclusion, NREM sleep supports the interrelation of information and during A1 phase prefrontal cortex produces divergent thinking.

Ritter et al. (2012) tested the effect of conditioning odors ( $\mathrm{N}=49,18-49$ years old), during sleep, on a creativity task (how to motivate somebody to volunteerism). Is it possible for the creativity task to be replayed during sleep by previously used stimuli? Researchers diffused orange-vanilla odor to participants, during a creativity task, in secret. One group slept and during sleep the same odor was diffused, while in the other two groups either mint was diffused or no odor. The group who smelled the same odor (orange-vanilla) offered more creative solutions and creativity was enhanced, in comparison to other groups.

Marguilho, et al. (2015) reviewed on sleep and creativity from 1990 to 2014. They found 11 studies in accordance with the criteria of inclusion. They found a positive correlation among creativity and sleep, but there were several, different definitions on creativity. In particular, both REM sleep, with dreams and recall of them, and NREM sleep contribute to the 
empowerment of creativity. In REM phase neurotransmitters of dream affect imagination and originality. In NREM phase interaction of distant information is activated. Those who are supposed to be creative can recall their dreams more. Those who prefer staying up till late at night have more flexible thought, divergent thinking and originality. The quality of sleep is significantly and positively related to creativity, while the duration of sleep is moderately and positively related.

In summary, sleep and creativity are related in an interesting way, in which special situations and ideas come up, that may not be possible to evoke during alertness. Time is an important factor for ideas or inspirations to be expressed, but sleep affects creativity more, through dreaming and neuro-synaptic functions. Moreover, NREM sleep causes a creative synthesis of information and if stimuli are added during sleep, then more creative responses are elicited.

\section{Conclusions}

In this review, the relations between sleep and cognitive abilities were examined. Memory is a basic and important cognitive function for learning. Perhaps that is the reason why there have been so many studies on sleep and memory. In addition, language is important and it is closely connected to the learning process. Especially, the acceleration of learning a foreign language attracts a lot of research attention. Problem-solving is also an important ability in academic and everyday life. It depends on fluid intelligence, mostly and it is affected by sleep positively. Creativity is a higher cognitive ability, a complex function which is promoted in education and can be physically enhanced, by sleeping.

In particular, NREM sleep boosts declarative memory, while REM sleep boosts procedural memory. Both phases of sleep contribute to memory consolidation, through selective memory in different tasks or through different frequencies in neuronal activity that is present in each phase. REM phase is more related to problem-solving and creative expressions than NREM phase. Sometimes, NREM sleep contributes, too.

Sleep recording by fMRI, EEG or Calcium measures are required when there are interventions in sleep patterns, in order to enhance cognitive abilities. Target Memory Reactivation technique uses audio or olfactory stimuli during learning that is repeated during sleep. This method causes declarative memory consolidation. Transcranial Direct Current Stimulation, during Slow Wave Sleep, also enhances declarative memory. Sound may be enhancive in each stage of sleep. Odor may be boosting only in light sleep.

Sleep can defuse noise of information during coding, reduces false memories and replays previous experiences, as it is reported by those who are woken up during dreaming. Sleep and auditory suggestions can boost learning a new vocabulary and grammatical rules. Emotions are significant in learning and if they are combined with sleep interventions, they affect learning and recall positively.

Higher cognitive abilities, such as problem-solving and creativity may be developed during a night-sleep. Moreover, through dreaming concepts may be generated or difficult problems may be solved. Many inventors changed the world by taking into account the ideas that were generated in their dreams.

Sleep, as a physical procedure, may enhance learning, so hypnopaedia may be another way to boost learning or cognitive abilities. Hypnopaedia might hack the brain and could accelerate cognition. Of course, more research is necessary to confirm these results though the use of TMR or other techniques, in different tasks and groups. These results may organize learning environments and sleeping routines accordingly. There could be different protocols for different learning tasks and different stages of sleep. It would be interested to test these methods in several groups of students, for example, with learning disabilities, ADHD, etc. In other studies, it is necessary to include personal traits and groups with learning interventions as usual. Several physical measures can be utilized in sleep-learning as evidence of neuroplasticity or as a tool for intervention. In addition, learning also means changing one's behavior. Suggestions during sleep could regulate behaviors, emotions and 
cognitive abilities. So, could hypnopaedia enhance positive behaviors, psychological well been or could it help students with behavior problems? That is a new research question. The more knowledge is derived from research on brain activity and cognitive abilities, even during sleep, the better practices and results could be suggested, for a higher level of cognition and well being. Finally, it seems that even the darkness of the night, during sleep, may light our minds.

\section{References}

Andrillon, T., Pressnitzer, D., Léger, D., \& Kouider, S. (2017). Formation and suppression of acoustic memories during human sleep. Nature Communications, 8(1). https://doi.org/10.1038/s41467-017-00071$\mathrm{Z}$

Ashton, J. E., Cairney, S. A., \& Gaskell, M. G. (2017). No effect of targeted memory reactivation during slow-wave sleep on emotional recognition memory. Journal of Sleep Research, 27(1), 129-137. https://doi.org/10.1111/jsr.12542

Batterink, Laura J., \& Paller, K. A. (2017). Sleep-based memory processing facilitates grammatical generalization: Evidence from targeted memory reactivation. Brain and Language, 167, 83-93. https://doi.org/10.1016/j.bandl.2015.09.003

Batterink, Laura J., Oudiette, D., Reber, P. J., \& Paller, K. A. (2014). Sleep facilitates learning a new linguistic rule. Neuropsychologia, 65, 169-179. https://doi.org/10.1016/j.neuropsychologia.2014.10.024

Batterink, Laura J., Westerberg, C., \& Paller, K. A. (2017). Vocabulary learning benefits from REM after slow-wave sleep. Neurobiology of Learning and Memory, 144, 102-113. https://doi.org/10.1016/j.nlm.2017.07.001

Batterink, L. J., Creery, J. D., \& Paller, K. A. (2016). Phase of Spontaneous Slow Oscillations during Sleep Influences Memory-Related Processing of Auditory Cues. Journal of Neuroscience, 36(4), 14011409. https://doi.org/10.1523/jneurosci.3175-15.2016

Beijamini, F., Pereira, S. I. R., Cini, F. A., \& Louzada, F. M. (2014). After Being Challenged by a Video Game Problem, Sleep Increases the Chance to Solve It. PLoS ONE, 9(1), e84342. https://doi.org/10.1371/journal.pone.0084342

Born, J., Rasch, B., \& Gais, S. (2006). Sleep to Remember. The Neuroscientist, 12(5), 410-424. https://doi.org/10.1177/1073858406292647

Budzynski, T. H. (2011). Twilight Learning Revisited1. Biofeedback, 39(4), 155-166. https://doi.org/10.5298/1081-5937-39.4.08

Burke, T. M., Scheer, F. A. J. L., Ronda, J. M., Czeisler, C. A., \& Wright, K. P. (2015). Sleep inertia, sleep homeostatic and circadian influences on higher-order cognitive functions. Journal of Sleep Research, 24(4), 364-371. https://doi.org/10.1111/jsr.12291

Cai, D. J., Mednick, S. A., Harrison, E. M., Kanady, J. C., \& Mednick, S. C. (2009). REM, not incubation, improves creativity by priming associative networks. Proceedings of the National Academy of Sciences, 106(25), 10130-10134. https://doi.org/10.1073/pnas.0900271106 
Cairney, S. A., Sobczak, J. M., Lindsay, S., \& Gaskell, M. G. (2017). Mechanisms of Memory Retrieval in Slow-Wave Sleep. Sleep, 40(9). https://doi.org/10.1093/sleep/zsx114

Carskadon, M. A., \& Dement, W. C. (2011). Monitoring and staging human sleep. In M. H. Kryger, T. Roth, \& W. C. Dement (Eds.), Principles and practice of sleep medicine, 5th edition, (p. pp 16-26). Elsevier Saunders.

Chen, Z., \& Wilson, M. A. (2017). Deciphering Neural Codes of Memory during Sleep. Trends in Neurosciences, 40(5), 260-275. https://doi.org/10.1016/j.tins.2017.03.005

Creery, J. D., Oudiette, D., Antony, J. W., \& Paller, K. A. (2015). Targeted Memory Reactivation during Sleep Depends on Prior Learning. Sleep, 38(5), 755-763. https://doi.org/10.5665/sleep.4670

Diekelmann, S., \& Born, J. (2010). The memory function of sleep. Nature Reviews Neuroscience, 11(2), 114-126. https://doi.org/10.1038/nrn2762

Drago, V., Foster, P. S., Heilman, K. M., Aricò, D., Williamson, J., Montagna, P., \& Ferri, R. (2011). Cyclic alternating pattern in sleep and its relationship to creativity. Sleep Medicine, 12(4), 361-366. https://doi.org/10.1016/j.sleep.2010.11.009

Ellenbogen, J. M., Hulbert, J. C., Jiang, Y., \& Stickgold, R. (2009). The Sleeping Brain's Influence on Verbal Memory: Boosting Resistance to Interference. PLoS ONE, 4(1), e4117. https://doi.org/10.1371/journal.pone.0004117

Fenn, K. M., Gallo, D. A., Margoliash, D., Roediger, H. L., \& Nusbaum, H. C. (2009). Reduced false memory after sleep. Learning \& Memory, 16(9), 509-513. https://doi.org/10.1101/lm.1500808

FICCA, G. (2004). What in sleep is for memory. Sleep Medicine, 5(3), 225-230. https://doi.org/10.1016/j.sleep.2004.01.018

Hu, P., Stylos-Allan, M., \& Walker, M. P. (2006). Sleep Facilitates Consolidation of Emotional Declarative Memory. Psychological Science, 17(10), 891-898. https://doi.org/10.1111/j.14679280.2006.01799.x

Landmann, N., Kuhn, M., Maier, J.-G., Feige, B., Spiegelhalder, K., Riemann, D., \& Nissen, C. (2016). Sleep Strengthens but does Not Reorganize Memory Traces in a Verbal Creativity Task. Sleep, 39(3), 705-713. https://doi.org/10.5665/sleep.5556

Marguilho, R., Jesus, S., Viseu, J., Domingues, R., Brandolim N., Becker, N., Matavelli, R., Quevedo, R., Buela-Casal, G.(2015). Sleep and creativity: a literature review. Advanced Research in Health, Education and Social Sciences: Towards a better practice. Sibiu, Romania.10.5682/9786062803797

Marshall, L. (2004). Transcranial Direct Current Stimulation during Sleep Improves Declarative Memory. Journal of Neuroscience, 24(44), 9985-9992. https://doi.org/10.1523/jneurosci.2725-04.2004

Monaghan, P., Sio, U. N., Lau, S. W., Woo, H. K., Linkenauger, S. A., \& Ormerod, T. C. (2015). Sleep promotes analogical transfer in problem solving. Cognition, 143, 25-30. https://doi.org/10.1016/j.cognition.2015.06.005 
Ngo, H.-V. V., Martinetz, T., Born, J., \& Mölle, M. (2013). Auditory Closed-Loop Stimulation of the Sleep Slow Oscillation Enhances Memory. Neuron, 78(3), 545-553. https://doi.org/10.1016/j.neuron.2013.03.006

Oghenero, O.-A. (2019). A Visuo-Spatial Understanding of Hypnopaedia. International Journal of Innovative Science and Research Technology, 4(1). https://ijisrt.com/wpcontent/uploads/2019/01/IJISRT19JA205.pdf

Oudiette, D., \& Paller, K. A. (2013). Upgrading the sleeping brain with targeted memory reactivation. Trends in Cognitive Sciences, 17(3), 142-149. https://doi.org/10.1016/j.tics.2013.01.006

Peigneux, P., Laureys, S., Delbeuck, X., \& Maquet, P. (2001). Sleeping brain, learning brain. The role of sleep for memory systems. Neuroreport, 12(18), A111-A124. https://doi.org/10.1097/00001756200112210-00001

Perogamvros, L., Dang-Vu, T. T., Desseilles, M., \& Schwartz, S. (2013). Sleep and dreaming are for important matters. Frontiers in Psychology, 4(474). https://doi.org/10.3389/fpsyg.2013.00474

Ritter, S. M., Strick, M., Bos, M. W., Van Baaren, R. B., \& Dijksterhuis, A. (2012). Good morning creativity: task reactivation during sleep enhances beneficial effect of sleep on creative performance. Journal of Sleep Research, 21(6), 643-647. https://doi.org/10.1111/j.1365-2869.2012.01006.x

Schönauer, M., Brodt, S., Pöhlchen, D., Breßmer, A., Danek, A. H., \& Gais, S. (2018). Sleep Does Not Promote Solving Classical Insight Problems and Magic Tricks. Frontiers in Human Neuroscience, 12(72). https://doi.org/10.3389/fnhum.2018.00072

Schreiner, T., \& Rasch, B. (2017). The beneficial role of memory reactivation for language learning during sleep: A review. Brain and Language, 167, 94-105. https://doi.org/10.1016/j.band1.2016.02.005

Schreiner, T., Lehmann, M., \& Rasch, B. (2015). Auditory feedback blocks memory benefits of cueing during sleep. Nature Communications, 6(1). https://doi.org/10.1038/ncomms9729

Shanahan, L. K., \& Gottfried, J. A. (2014). Olfactory Insights into Sleep-Dependent Learning and Memory. Progress in Brain Research, 208, 309-343. https://doi.org/10.1016/b978-0-444-63350-7.000127

Shimizu, R. E., Connolly, P. M., Cellini, N., Armstrong, D. M., Hernandez, L. T., Estrada, R., Aguilar, M., Weisend, M. P., Mednick, S. C., \& Simons, S. B. (2018). Closed-Loop Targeted Memory Reactivation during Sleep Improves Spatial Navigation. Frontiers in Human Neuroscience, 12(28). https://doi.org/10.3389/fnhum.2018.00028

Sio, U. N., Monaghan, P., \& Ormerod, T. (2013). Sleep on it, but only if it is difficult: effects of sleep on problem solving. Memory \& Cognition, 41(2), 159-166. https://doi.org/10.3758/s13421-012-0256-7

Stickgold, R., \& Walker, M. P. (2005). Sleep and Memory: The Ongoing Debate. Sleep, 28(10), 12251227. https://doi.org/10.1093/sleep/28.10.1225

Tononi, G., \& Cirelli, C. (2003). Sleep and synaptic homeostasis: a hypothesis. Brain Research Bulletin, 62(2), 143-150. https://doi.org/10.1016/j.brainresbull.2003.09.004 
Ulrich, D. (2016). Sleep Spindles as Facilitators of Memory Formation and Learning. Neural Plasticity, 2016, 1-7. https://doi.org/10.1155/2016/1796715

Van Der Werf, Y. D., Altena, E., Schoonheim, M. M., Sanz-Arigita, E. J., Vis, J. C., De Rijke, W., \& Van Someren, E. J. W. (2009). Sleep benefits subsequent hippocampal functioning. Nature Neuroscience, 12(2), 122-123. https://doi.org/10.1038/nn.2253

van Dongen, E. V., Takashima, A., Barth, M., Zapp, J., Schad, L. R., Paller, K. A., \& Fernandez, G. (2012). Memory stabilization with targeted reactivation during human slow-wave sleep. Proceedings of the National Academy of Sciences, 109(26), 10575-10580. https://doi.org/10.1073/pnas.1201072109

van Rijn, E., Lucignoli, C., Izura, C., \& Blagrove, M. T. (2016). Sleep-dependent memory consolidation is related to perceived value of learned material. Journal of Sleep Research, 26(3), 302-308. https://doi.org/10.1111/jsr.12457

Wagner, U., Gais, S., Haider, H., Verleger, R., \& Born, J. (2004). Sleep inspires insight. Nature, 427(6972), 352-355. https://doi.org/10.1038/nature02223

Walker, M. P. (2008). Cognitive consequences of sleep and sleep loss. Sleep Medicine, 9(1), S29-S34. https://doi.org/10.1016/s1389-9457(08)70014-5

Walker, M. P., \& Stickgold, R. (2006). Sleep, Memory, and Plasticity. Annual Review of Psychology, 57(1), 139-166. https://doi.org/10.1146/annurev.psych.56.091103.070307

Walker, M. P., Liston, C., Hobson, J. A., \& Stickgold, R. (2002). Cognitive flexibility across the sleepwake cycle: REM-sleep enhancement of anagram problem solving. Cognitive Brain Research, 14(3), 317-324. https://doi.org/10.1016/s0926-6410(02)00134-9

Wamsley, E. J., Tucker, M., Payne, J. D., Benavides, J. A., \& Stickgold, R. (2010). Dreaming of a Learning Task Is Associated with Enhanced Sleep-Dependent Memory Consolidation. Current Biology, 20(9), 850-855. https://doi.org/10.1016/j.cub.2010.03.027

Williams, S. E., \& Horst, J. S. (2014). Goodnight book: sleep consolidation improves word learning via storybooks. Frontiers in Psychology, 5(184). https://doi.org/10.3389/fpsyg.2014.00184 